\title{
PAULO FREIRE NA GENEALOGIA DA PEDAGOGIA DECOLONIAL: UMA LEITURA DE EXTENSÃO OU COMUNICAÇÃO?
}

\author{
BRUNO dOS SANTOS JOAQUIM \\ Universidade Federal do Estado de São Paulo (UNIFESP), Santos, São Paulo, Brasil \\ LUCILA Maria Pesce de OliveIRA \\ Universidade Federal do Estado de São Paulo (UNIFESP), Guarulhos, São Paulo, Brasil
}

\begin{abstract}
REsUMO: O presente artigo caracteriza-se como um estudo teórico-conceitual que procura discutir as contribuições da obra Extensão ou Comunicação?, de Paulo Freire, dentro da genealogia da pedagogia decolonial latino-americana. Inserida na corrente teórica Modernidade/Colonialidade, a pedagogia decolonial constitui-se como um projeto político, social, epistêmico e ético, expresso pela interculturalidade crítica, que aposta na evocação de conhecimentos outrora marginalizados e de uma postura insurgente diante das estruturas rígidas resultantes do binômio Modernidade/Colonialidade. Na obra Extensão ou Comunicação?, Paulo Freire apresenta elementos que compõem parte das bases desse pensamento, como a crítica à suposta neutralidade científica; a invasão cultural como ação de silenciamento e reificação do ser humano oprimido; a hierarquização do saber e o preconceito epistêmico; a conscientização social como estratégia de transformação. Conclui-se que a obra pode ser considerada, dentro dos marcos do desenvolvimento do pensamento freiriano, precursora da pedagogia decolonial.
\end{abstract}

Palavras-chave: Paulo Freire. Pedagogia Decolonial. Decolonialidade.

Educar e educar-se, na prática da liberdade, não é estender algo desde a "sede do saber" até a "sede da ignorância" para "salvar", com este saber, os que habitam

nesta.

Paulo Freire

INTRODUÇÃO

O presente artigo caracteriza-se como um estudo teórico-conceitual que procura discutir as contribuições da obra Extensão ou Comunicação? $(1969 / 2020)^{2}$, de Paulo Freire, dentro da genealogia da pedagogia decolonial latino-americana. Apontado como um precursor do pensamento decolonial por autores como Walsh (2009), Penna (2014) e Mota Neto (2018), ao lado de pensadores como Frantz Fanon ${ }^{3}$ e Orlando Fals Borda ${ }^{4}$, Paulo Freire tem uma vasta e mundialmente reconhecida produção intelectual. A 
obra Extensão ou Comunicação?, a terceira publicada pelo autor, é referência em cursos de graduação e pós-graduação sobre as temáticas da extensão universitária, divulgação científica, educação popular e educação de adultos. Como ela se vincula à construção das bases do pensamento pedagógico decolonial? Quais elementos presentes nessa obra dialogam com a perspectiva teórica Modernidade/Colonialidade? Quais as possibilidades de uma leitura decolonial desse ensaio freiriano?

Há cerca de vinte anos um grupo de intelectuais latino-americanos, de diversas áreas do conhecimento, vem ganhando espaço nas pesquisas e no pensamento do campo das ciências sociais e da educação. Intelectuais decoloniais, como a linguista norte-americana radicada no Equador Catherine Walsh, o sociólogo peruano Aníbal Quijano, o semiólogo argentino Walter Mignolo, entre outros, vêm propondo um giro epistêmico capaz de produzir novos conhecimentos e outras compreensões simbólicas do mundo. A partir da denúncia do mito da fundação da modernidade e da perversa persistência da colonialidade do poder e do racismo epistêmico, essa corrente propõe "a construção de um novo espaço epistemológico que promove a interação entre os conhecimentos subalternizados e os ocidentais, questionando a hegemonia destes e a invisibilização daqueles" (OLIVEIRA, 2016, p. 3).

No seio dessa corrente teórica, no campo da educação, os estudos da Modernidade/Colonialidade vêm apresentando a proposta de uma pedagogia decolonial. Trata-se, para Walsh (2009), de um projeto político, social, epistêmico e ético, expresso pela interculturalidade crítica, que aposta na evocação de conhecimentos outrora marginalizados e de uma postura insurgente diante das amarras do binômio Modernidade/Colonialidade. Ela pode ser compreendida "como processo e prática sociopolíticos produtivos e transformadores assentados nas realidades, subjetividades, histórias e lutas das pessoas, vividas num mundo regido pela estrutura colonial" (WALSH, 2009, p. 26).

Publicado originalmente em espanhol, em 1969, Extensão ou Comunicação? é um ensaio em que Paulo Freire analisa a relação entre técnicos agrônomos e camponeses, no contexto da reforma agrária no Chile. A obra foi escrita enquanto o educador estava no exílio e atuava junto ao Movimento de Reforma Agrária da Democracia Cristã e ao Instituto de Capacitación y Investigação en Reforma Agraria (Icira), ligado a Unesco. O autor critica o uso do termo "extensão", que considera um equívoco gnosiológico, posicionando-se criticamente diante de seu caráter antidialógico que resulta no que chama de invasão cultural. Há, na atuação do agrônomo, segundo ele, um processo de desumanização descomprometido com uma educação libertadora. Em um movimento de invasão cultural, o agrônomo desconsidera a visão de mundo e os saberes do camponês (FREIRE, 2020).

Este estudo identifica que alguns elementos da pedagogia decolonial já estavam em debate por Freire ao final da década de 1960. Em especial, verifica-se os seguintes elementos decoloniais em Extensão ou Comunicação? crítica à suposta neutralidade científica; invasão cultural como ação de silenciamento e reificação do homem oprimido; hierarquização do saber e preconceito epistêmico; e conscientização social como estratégia de transformação. 
Na primeira parte deste artigo, analisa-se a pedagogia decolonial e sua relação com o arcabouço freiriano. Na segunda parte, procura-se destrinchar a obra Extensão ou Comunicação? a fim de identificar pontualmente sua contribuição teórica para o pensamento decolonial. Por fim, são tecidas considerações sobre as possibilidades de pesquisas futuras com base nas conclusões deste estudo teórico.

\title{
PAULO FREIRE NA GENEALOGIA DA PEDAGOGIA DECOLONIAL
}

A relação entre o pensamento de Paulo Freire e a corrente Modernidade/Colonialidade é identificada por diversos estudos recentes, a exemplo de Walsh (2009), Penna (2014) e Mota Neto (2018). Há cerca de duas décadas, um conjunto de intelectuais latino-americanos vem sendo conclamado a discutir os contextos de desigualdade da educação no Brasil e em toda a região. Em diálogo com autores das décadas de 1960, como Paulo Freire, Frantz Fanon e Fals Borda, tais intelectuais alicerçaram as bases do que hoje se chama pensamento decolonial.

\begin{abstract}
O termo decolonial deriva de uma perspectiva teórica que estes autores expressam, fazendo referência às possibilidades de um pensamento crítico a partir dos subalternizados pela modernidade capitalista e, na esteira dessa perspectiva, a tentativa de construção de um projeto teórico voltado para o pensamento crítico transdisciplinar, caracterizando-se também como força política para se contrapor às tendências acadêmicas dominantes de perspectiva eurocêntrica de construção do conhecimento histórico e social (OLIVEIRA, 2016, p. 437).
\end{abstract}

Esses teóricos compreendem que a colonialidade e a modernidade são duas faces da mesma moeda, isto é, questionam uma geopolítica do conhecimento que afirmou suas teorias a partir de um paradigma supostamente universal, como um modelo único de fazer ciência, ao mesmo tempo em que invisibilizou e silenciou outras perspectivas (WALSH; OLIVEIRA; CANDAU, 2018). Para essa corrente, a modernidade não pode ser pensada sem a colonialidade, pois "o silenciamento, ignorância e inferiorização do outro são constitutivos da modernidade, por isso a colonialidade é pensada como um lado oculto e presente na modernidade" (BERNARDINO-COSTA, 2015, p. 41).

Entre os principais conceitos dessa perspectiva estão o mito da fundação da modernidade, compreendido como criação de uma suposta razão universal pelas classes dominantes europeias; o racismo epistêmico, referindo-se à negação de epistemologias outras que não as eurocêntricas; e a própria pedagogia decolonial (PENNA, 2014).

Bernardino-Costa (2015), ao analisar as narrativas das trabalhadoras domésticas sindicalizadas, identifica entre elas uma produção de conhecimento baseado no saber oral como uma contribuição ao processo de construção de um conhecimento decolonial. $O$ autor faz uma detalhada sistematização da constituição dessa corrente de pensamento com destaque especial para a contribuição da sociologia das ausências, desenvolvida por Boaventura de Sousa Santos, do conceito de colonialidade do poder, de Aníbal Quijano, e do conceito de diferença colonial, de Walter Mignolo.

A sociologia das ausências fundamenta-se na crítica à hierarquização dos conhecimentos, em especial, aquilo que Boaventura de Sousa Santos define como razão 
metonímica, que reivindica o conhecimento hegemônico filosófico e científico como única forma legítima de racionalidade. Nesse sentido, impõe-se a necessidade de emersão de experiências ignoradas e silenciadas, produzidas por grupos sociais subalternizados, visando substituir uma monocultura do saber (razão metonímica) por uma ecologia de saberes capaz de reconhecer a diversidade epistemológica do mundo e superar o falso universalismo baseado no mito do sujeito moderno e universal (SANTOS, 2006).

Para Aníbal Quijano (2005 apud BERNARDINO-COSTA, 2015), há um persistente legado do colonialismo na América Latina, que permanece mesmo após a formação dos Estados independentes na região. A descolonização está incompleta, pois ainda se faz necessária uma descolonização em termos de raça-etnia, gênero, trabalho, religião e linguagem. Nesse sentido, superado o colonialismo, enquanto processo histórico de exploração, ainda é preciso enfrentar as amarras da colonialidade do poder, do saber e do ser.

\begin{abstract}
A colonialidade do poder é o padrão de poder que se constitui juntamente com o capitalismo moderno/colonial eurocentrado, que teve início com a conquista da América em 1492. O sistema-mundo moderno/colonial, que se constituiu a partir daquela data, deu origem a um novo padrão de poder mundial fundamentado na ideia de raça, que passou a classificar a população mundial, produzindo identidades raciais historicamente novas, que ficaram, por vezes, associadas a hierarquias, lugares, papéis sociais correspondentes aos padrões de dominação (QUIJANO, 2005, p. 106 apud BERNARDINO-COSTA, 2015, p. 43).
\end{abstract}

Há um conjunto de hierarquias criadas pela colonialidade do saber, em decorrência desta persistente configuração das relações de poder, que, mesmo após a emergência dos Estados independentes, influencia diversos âmbitos da vida social na América Latina. Há, portanto, a necessidade de se colocar em primeiro plano os saberes subalternizados por esta estrutura perversa. Walter Mignolo (2003) compreende que há um pensamento de fronteira que emerge do confronto entre o conhecimento moderno europeu e os conhecimentos produzidos no Sul Global, isto é, que emerge da diferença colonial. Esse pensamento de fronteira é plural e representa novas possibilidades de ação para o enfrentamento e reconfiguração das estruturas de poder historicamente erguidas. $O$ pensamento de fronteira insurge-se contra a colonialidade do saber.

A pedagogia decolonial é constituinte do pensamento fronteiriço, na medida em que parte do projeto decolonial que procura desvelar o lado sombrio da modernidade e contribuir para a emancipação dos grupos sociais subalternizados e oprimidos pelo padrão moderno/colonial. Na perspectiva de Oliveira (2016, p. 439), a pedagogia decolonial constitui-se em "expressar o colonialismo que construiu a desumanização dirigida aos subalternizados pela modernidade europeia e pensar na possibilidade de crítica teórica a geopolítica do conhecimento". Trata-se de uma prática política no âmbito educacional que se propõe a visibilizar, enfrentar e transformar as estruturas sociais permeadas pela lógica da colonialidade. É, portanto, uma práxis de 
(re)criação de condições sociais, políticas e culturais fora da esfera das formulações teóricas eurocentradas e contrapostas às lógicas educativas hegemônicas. A práxis decolonial, em diálogo com a interculturalidade crítica, tem um caráter insurgente e plural. Para Walsh (2009), é oportuno pensar e significar hoje uma perspectiva de pedagogias que se relacionem com os projetos e perspectivas da interculturalidade crítica e da decolonialidade.

\begin{abstract}
Pedagogias que dialogam com os antecedentes crítico-políticos que, por sua vez, se originam nas lutas e práxis de orientação decolonial [...]; pedagogias que se esforcem para transgredir, deslocar e incidir uma negação ontológica, epistêmica e cosmogônica-espiritual que tenha sido - e é - estratégia, fim e resultado do poder da colonialidade. Quer dizer, 'pedagogia(s) decolonial(is)' (WALSH, 2009, p. 15).
\end{abstract}

O sentido dado ao conceito de interculturalidade crítica, sobre a qual se ergue a pedagogia decolonial, não se refere apenas à ação de incorporar os grupos excluídos dentro das estruturas vigentes, mas "assinalar a necessidade de visibilizar, enfrentar e transformar as estruturas e instituições que diferencialmente posicionam grupos, práticas e pensamentos dentro de uma ordem e lógica que, por sua vez e todavia, é racial moderno-ocidental e colonial" (WALSH, 2009, p. 12).

Portanto, decolonizar na educação é construir outras formas de compreender e de se fazer pedagogia, identificando e denunciando a presença da colonialidade no pensamento e nas políticas educacionais. Essa perspectiva tem um sentido contra hegemônico e sua genealogia encontra-se nos movimentos sociais de resistência ao problema estrutural-colonial-capitalista. Na coletânea organizada por Streck, Moretti e Adams (2019), apresenta-se algumas heranças latino-americanas da pedagogia decolonial, ligada a movimentos indígenas, quilombolas e de outros grupos sociais subalternizados no passado e no presente que desafiaram e desafiam as estruturas sociais, políticas e epistêmicas da colonialidade.

A pedagogia decolonial se alia à pedagogia crítica, desenvolvida por Paulo Freire a partir da década de 1960. Essa aproximação se aloca principalmente no caráter de insurgência social, cultural, política, epistêmica e educativa que ambas propõem. Não se trata, como afirma Walsh (2009), de pensar a pedagogia decolonial como uma manifestação contemporânea da pedagogia crítica, mas de identificar a posição desta na genealogia daquela. Há um conjunto de contribuições do pensamento freiriano para a constituição da pedagogia decolonial.

Mota Neto (2018) identifica cinco elementos na obra de Freire e Fals Borda que sustentam a tese de que os pensadores são antecessores do debate da colonialidade. Seu estudo considera que, para ambos, a concepção de pedagogia: "a) requer educadores subversivos; b) parte de uma hipótese de contexto; c) valoriza as memórias coletivas dos movimentos de resistência; d) está em busca de outras coordenadas epistemológicas; e) afirma-se como uma utopia política" (MOTA NETO, 2018, p. 7). Essa concepção, como se vê, coaduna-se ao pensamento pedagógico decolonial.

Tanto na pedagogia decolonial quanto no pensamento freiriano se identificam elementos comuns, como o reconhecimento do ato de educar como um ato político; o desenvolvimento de uma ética humana contrária às opressões; a crítica à neutralidade 
da ciência; a crítica à hierarquização do saber e o preconceito epistêmico; a perspectiva de humanização do homem por meio da ação consciente; a rebeldia como práxis política-pedagógica de existência; a invasão cultural como ação de silenciamento dos oprimidos; o papel do educador como agente de empoderamento e transformação social; e o papel do colonialismo no sistema de opressão.

Esses elementos são encontrados em toda a produção intelectual de Paulo Freire. Entretanto, o reconhecimento mais claro do papel do colonialismo na opressão pode ser identificado somente a partir da publicação de Pedagogia da Esperança (1992/2013). Nesta obra, Freire, em um repensar do seu diálogo intelectual com Fanon, relaciona aspectos políticos e epistêmicos das opressões com a racialização, dentro do marco da descolonização.

Walsh (2009) diferencia as compreensões de Fanon e Freire acerca dos processos de humanização e desumanização exatamente pela ausência, em Freire, de uma ênfase maior ao reconhecimento da colonialidade como elemento central de desumanização. Para Freire, segundo Walsh (2009), a desumanização é um projeto enraizado na realidade e no contexto histórico concreto pautado por opressões múltiplas, mas não é apresentado como produto direto do colonialismo. Assim, tanto a humanização como a desumanização seriam possibilidades para o homem como ser incompleto em Freire, enquanto que, para Fanon, a desumanização é resultado imediato de um projeto inacabado de descolonização e, portanto, a humanização requer a descolonização em um sentido amplo.

Penna (2014) analisa a convergência entre a obra mais difundida de Paulo Freire, Pedagogia do Oprimido (1968/2002), e a perspectiva decolonial latino-americana, assinalando seu caráter pedagógico para o campo das ciências sociais. Segundo a autora, é possível identificar fortes afinidades entre a obra e o paradigma da Modernidade/Colonialidade, especialmente na proposta de desconstruir o mito da estrutura opressora eurocentrada. Ressalta-se o destaque dado pela autora à centralidade da linguagem nesse processo de desconstrução das estruturas modernocoloniais. Linguagem e discurso são centrais no pensamento freiriano e nos estudos decoloniais, na medida em que, em ambos, a pronúncia da palavra não deve ser prerrogativa apenas de alguns. Pelo contrário, a reconquista do direito de enunciação e de pronúncia do mundo faz parte do projeto de uma educação libertadora: "Seu objetivo de libertação das classes oprimidas está diretamente ligado à conquista da capacidade destas de também dizer a palavra, dizê-la conforme sua forma de perceber a realidade ou, se poderia dizer, emiti-la a partir de seu lugar de fala" (PENNA, 2014, p. 192).

A palavra aqui adquire um sentido amplo, que se relaciona com a concepção da linguagem como elemento central da experiência social. lanni (2008) destaca o sentido da palavra que se transforma na trama das relações sociais e simboliza modos de ser. Para o autor, a linguagem:

revela-se produto e condição das formas de sociabilidade e dos jogos das forças sociais, constituindo-se como componente essencial das configurações histórico-sociais de vida, trabalho e cultura. A linguagem simultaneamente taquigrafa e constitui as 
JOAQUIM, B. dos S.; OLIVEIRA, L. M. P. de.

relações, os processos e as estruturas da vida social em geral, tanto quanto as produções e criações que conformam a sociedade, em âmbito local, nacional, regional e mundial (IANNI, 2008, p. 25).

Nesse sentido, linguagem é pensamento e constitui visão de mundo. Como as línguas são plurais, as visões de mundo e consciências de indivíduos e coletividades também o são. Como é na linguagem que se expressam as identidades, é também por meio dela que o projeto decolonial se articula. Para Paulo Freire (2020), é por meio da palavra que se constrói uma educação como prática de liberdade, pois para ele, educação é diálogo em dimensão coletiva. É nessa perspectiva que se apresenta, a seguir, uma leitura decolonial da obra Extensão ou Comunicação?, um ensaio crítico à prática extensionista promovida por técnicos agrônomos no contexto da reforma agrária chilena, que desconsidera a palavra do camponês, não dialoga com ela e, portanto, desrespeita sua visão de mundo e desumaniza-o.

\title{
A PEDAGOGIA DECOLONIAL EM EXTENSÃO OU COMUNICAÇÃO?
}

Exilado com sua família no Chile após o Golpe de 1964, Paulo Freire atuou, a convite do agrônomo e político Jacques Chonchol, no Instituto de Desarrollo Agropecuario (Indap). O país vivia um contexto democrático e de agitação política após a vitória eleitoral do democrata-cristão Eduardo Frei Montalva no pleito de 1964 sobre a coalizão de esquerda liderada por Salvador Allende. Segundo Haddad (2019), a combinação de liberdade política, acolhimento e oferta de empregos ajudou a família Freire e a comunidade de lideranças brasileiras de diversos campos de atuação a se exilar em Santiago.

A principal função do Indap era auxiliar na organização sindical camponesa e desenvolver uma ação educativa junto aos trabalhadores rurais. A instituição apoiava os pequenos produtores com oferta de crédito e formação técnica com o objetivo de melhorar sua produtividade. Ainda nos primeiros meses, Paulo Freire acompanhou um grupo de funcionários da instituição que levantavam dados sobre a zona rural chilena.

\begin{abstract}
Contrariado com o método de trabalho, Paulo dialogou com os colegas sobre o modo de conceber pesquisas dessa natureza e propôs uma alternativa: em vez de os agentes pesquisarem a realidade dos habitantes do campo, solicitarem aos camponeses para que os auxiliassem a levantar suas principais questões, e esses seriam os temas abordados nas aulas pelas equipes de formação. Dessa maneira, partindo do olhar dos camponeses sobre o próprio contexto, a população agrícola estaria aprendendo com o estímulo e a orientação da equipe técnica, assim como os funcionários do Indap aprenderiam com a perspectiva camponesa (HADDAD, 2019, p. 86-87).
\end{abstract}

É no contexto de sua atuação no Indap que Paulo Freire produz Extensão ou Comunicação?, publicado pelo próprio Instituto somente em 1969, quando ele já havia iniciado seu trabalho junto ao Instituto de Capacitación y Investigação en Reforma Agraria (Icira), organização ligada à Unesco. Nesse período, desenvolve capacitação de equipes do governo chileno que atuavam na alfabetização de adultos e mantém sua 
intensa produção intelectual. Em 1967, com base em sua tese de doutoramento, publica Educação como prática de liberdade, livro em que sistematiza sua filosofia educacional, além de suas experiências com alfabetização de adultos em Angicos e com a formulação da Campanha Nacional de Alfabetização no Ministério da Educação e Cultura, onde atuou nos meses anteriores ao Golpe. No mesmo ano escreve Pedagogia do Oprimido, sua obra mais difundida, publicada no ano seguinte.

Sua produção intelectual desse período é fortemente influenciada pela perspectiva humanista e crítica à tradição antidemocrática da educação na América Latina. Observa-se nas publicações do Chile uma aproximação aos quadros de referência marxistas e aos estudos do psiquiatra Frantz Fanon. O diálogo entre os autores pode ser percebido em suas análises sobre a relação entre colonizador e colonizado (opressor e oprimido), isto é, a construção do oprimido pelo opressor, que engendra a negação de uma identidade própria e a imposição de outra (MARTINS, 2012).

Há uma tese entre os comentadores da obra de Paulo Freire que afirma que essas suas primeiras produções são carregadas de uma visão social desenvolvimentista, dentro de um marco pedagógico idealista, e que sua obra deixaria essa perspectiva ingênua na direção de uma crítica mais contundente com as suas publicações posteriores. No entanto, não há um consenso em torno dessa ideia. Martins (2012), por exemplo, identifica um processo de continuidade em seu pensamento, marcado pelo aprofundamento de algumas de suas concepções políticas já presentes nas suas primeiras obras.

A obra Extensão ou Comunicação? apresenta quatro elementos que se alocam na raiz do processo de aprofundamento crítico freiriano e que dialogam com a pedagogia decolonial: a) crítica à hierarquização do saber e ao preconceito epistêmico; b) crítica à invasão cultural como ação de silenciamento e reificação do oprimido; c) crítica à neutralidade da ciência e da técnica; e d) conscientização social como estratégia de transformação.

\section{A) CRÍtICA À HIERARQUIZAÇÃo do SABER E AO PRECONCEITO EPISTÊMICO}

No primeiro capítulo, Paulo Freire tece uma crítica ao modelo de atividades de extensão universitária e ao próprio uso do termo "extensão". Em sua visão, a extensão, como prática de transmissão do conhecimento técnico-científico para comunidades rurais, reifica o homem, transforma-o em coisa, e compreende uma hierarquização de diferentes mundos.

\footnotetext{
Parece-nos, entretanto, que a ação extensionista envolve, qualquer que seja o setor em que se realize, a necessidade que sentem aqueles que a fazem de ir até a "outra parte do mundo", considerada inferior, para, à sua maneira, "normalizá-la". Para fazê-la mais ou menos semelhante a seu mundo (FREIRE, 2020, p. 20).
}

Nota-se que o educador engendra uma argumentação crítica acerca da posição de superioridade em que se coloca o saber técnico-científico-moderno-colonial, em detrimento de outros saberes. A ação extensionista pretende fazer com que os grupos 
que a recebem substituam os seus conhecimentos por outros. Ela é, nesse sentido, antidialógica, promotora e promovida por uma absolutização da ignorância, um preconceito epistêmico que representa uma descrença no homem simples do campo e "uma subestimação do seu poder de refletir, de sua capacidade de assumir o papel verdadeiro de quem procura conhecer: o de sujeito desta procura. Daí a preferência por transformá-lo em objeto do conhecimento que se lhe impõe" (FREIRE, 2020, p. 56).

A educação como prática de liberdade se dá por meio de uma relação dialógica, que ocorre na relação entre os sujeitos. Trata-se, para Freire (2020), de comunicação, não de extensão. Nesse sentido, o agrônomo-educador e o camponês aprendem juntos em um processo de coparticipação dos sujeitos no ato de pensar, isto é, em um processo de dialogia. O pensamento tem uma dupla função, cognoscitiva e comunicativa, e a inteligibilidade e a comunicação se dão simultaneamente. Portanto, o papel do agrônomo-educador não pode ser o de discursar e o papel do agricultor não pode ser o de arquivar informações. "A educação é comunicação, é diálogo, na medida em que não é transferência de saber, mas um encontro de sujeitos interlocutores que buscam significação dos significados" (FREIRE, 2020, p. 89).

Mais adiante, o autor apresenta sua perspectiva humanista acerca da educação e da postura que, em sua visão, o agrônomo-educador comprometido com a educação libertadora deve ter em seu processo de comunicação com o camponês. Identifica-se em seu texto uma crítica à ideia de homem ideal, marcada pela intemporalidade e por uma espécie de mito. O autor busca um "humanismo que não se nutra de visões de um homem ideal, fora do mundo; de um perfil de homem fabricado pela imaginação, por mais bem-intencionada que seja quem o imagine" (FREIRE, 2020, p. 96).

Esta ideia crítica acerca da universalidade caracteriza fortemente a análise da corrente Modernidade-Colonialidade. Isso porque a modernidade europeia, advinda das revoluções burguesas, do lluminismo e da consolidação do capitalismo, que traz consigo o colonialismo e a colonialidade, forjou, subjetiva e objetivamente, uma ideia de Homem universal. Esta ideia legitima os saberes hegemônicos e deslegitima saberes outros. A crítica de Paulo Freire à hierarquização do saber, ao preconceito epistêmico e a este tipo de humanismo que pressupõe universalidade é uma das chaves de compreensão de seu pensamento como precursor dos estudos decoloniais.

Assim como Freire (2020) se opõe à ideia de mito de universalidade, rechaçando uma perspectiva evolucionista, Dussel (2005) analisa os mitos da modernidade eurocêntrica como elementos centrais da colonialidade. Os mitos da modernidade se fundamentam na ideia de que a civilização moderna seria mais desenvolvida e superior, o que moralmente a obrigaria a agir para desenvolver também os considerados mais primitivos, bárbaros, atrasados. Desse modo, haveria um caminho unilinear de desenvolvimento, assim como obstáculos para a modernização que precisariam ser vencidos, nem que para isso seja necessário o uso da violência. O bárbaro que se opõe ao processo civilizador teria culpa pelo seu atraso e pelo processo inevitável de sofrimento, causado pela necessidade de romper barreiras para a modernização e, portanto, as vítimas produzidas representariam o custo do processo civilizatório da modernidade.

É preciso estar atento para que o discurso em defesa da interculturalidade, presente no pensamento freiriano e decolonial, não seja submetido a uma racionalidade instrumental. Segundo Walsh (2009), avança na América Latina desde o final do século 
passado uma retórica multicultural-neoliberal, arraigada em uma interculturalidade funcional, que, diante das ações insurgentes de povos subalternizados, procura neutralizar e esvaziar seu significado efetivo e converter a interculturalidade em uma estratégia para a docilidade, estabilidade social e crescimento econômico. O falso discurso da integração presente no projeto vigente de globalização pode servir apenas como ferramenta para uma recolonização.

Nesse sentido, para uma pedagogia crítica e decolonial, não basta apenas incluir saberes e epistemes outrora excluídos nas mesmas relações e instituições historicamente constituídas, mas subverter suas estruturas. Pouco vale o reconhecimento de identidades e saberes sem mudança radical das estruturas opressoras.

\section{B) INVASÃO CULTURAL COMO AÇÃO DE SILENCIAMENTO E REIFICAÇÃO DO OPRIMIDO}

Ao referir-se à imposição da técnica do agrônomo-educador sobre os agricultores por meio da extensão, Freire (2020) invoca o conceito de invasão cultural e atribui a ela um processo de desumanização e silenciamento dos grupos subalternizados. A invasão cultural é a atitude contrária à educação como prática de liberdade, é antidialógica, pois manipula, escraviza e oprime o sujeito, impedindo que ele se reconheça como pessoa, que atue como sujeito e seja, de fato, agente do processo histórico. A relação entre invasor e invadidos interrompe qualquer possibilidade de diálogo, na medida em que:

\footnotetext{
O primeiro atua, os segundos têm ilusão de que atuam na atuação do primeiro; este diz a palavra; os segundos, proibidos de dizer a sua, escutam a palavra do primeiro. $O$ invasor pensa, na melhor das hipóteses, sobre os segundos, jamais com eles; estes são pensados por aqueles. O invasor prescreve; os invadidos são pacientes da prescrição (FREIRE, 2020, p. 49).
}

Sem diálogo, a ação extensionista adquire um papel de domesticação, de persuasão, de manipulação. O conteúdo do que é estendido, isto é, o conhecimento técnico-científico, permanece estático, não há condições para se transformar, pois somente "o sujeito que estende é, enquanto ator, ativo, em face de 'espectadores' em quem deposita o conteúdo que estende" (FREIRE, 2020, p. 27).

Assim, a invasão cultural pressupõe conquista, dominação, manipulação e messianismo. É um elemento do processo histórico colonial e de persistência da colonialidade mesmo após os processos de independência dos Estados nacionais. A invasão cultural implica o silenciamento de quem é invadido, isto é, grupos historicamente subalternizados por uma estrutura rígida que os inferioriza, demarcando a colonialidade do saber denunciada por Quijano (2005 apud BERNARDINO-COSTA, 2015).

Ao analisar o desenvolvimento da reforma agrária chilena em Extensão ou Comunicação?, Paulo Freire (2020, p. 76) reitera que "é urgente que nos defendamos da concepção mecanicista. Em sua ingenuidade e estreiteza de visão, tende a desprezar a 
contribuição fundamental de outros saberes". Nesse sentido, subverter a ordem da colonialidade passa pela insurgência de pedagogias que se oponham a invasão cultural, tal qual a pedagogia freiriana e a pedagogia decolonial.

A ação de subversão é, como afirma Mota Neto (2018), a busca por novas coordenadas epistemológicas, mais autônomas e capazes de representar o ponto de vista do Sul Global. É também devolver a palavra ao oprimido, marcando, assim, a devida relevância ao discurso produzido a partir do pensamento de fronteira, conforme assinala Mignolo (2003 apud BERNARDINO-COSTA, 2015). Acima de tudo, trata-se de reconhecer como imprescindível a presença das epistemes silenciadas nos processos pedagógicos, seja na educação não formal, na educação popular, na escola básica ou na universidade.

\section{C) CRÍTICA À NEUTRALIDADE DA CIÊNCIA E DA TÉCNICA}

Em diversas passagens de Extensão ou Comunicação?, Paulo Freire (2020) faz considerações acerca da falsa ideia de neutralidade da ciência e da técnica e acerca do papel do agrônomo-educador. As ideias de homem ideal e de hierarquização de saberes sustentam-se, entre outras estruturas, na concepção de que existe uma forma neutra e única de compreender a realidade, que é universal e desprovida de sentido históricopolítico-social.

Para os estudos decoloniais, desconstruir essa ideia é um caminho para a compreensão do papel da colonialidade na imposição de visões de mundo aos povos subalternizados. Além disso, é também um caminho para que se faça ouvir os movimentos de resistência que, historicamente, lutam pelo reconhecimento de suas identidades e epistemes, baseadas nos irredutíveis e incomensuráveis saberes ancestrais. A farsa da neutralidade científica é um dos pilares da colonialidade do poder, do saber e do ser. Paulo Freire (2020) é categórico quanto a isso: "Quem fala em neutralidade são precisamente os que temem perder o direito de usar de sua ineutralidade em seu favor" (FREIRE, 2020, p. 103).

Paulo Freire (2020) se posiciona entre a crítica de uma concepção contrária à transformação, que nega a ciência e a técnica, e a sua concepção mítica, que impugna à ciência e à técnica uma função salvadora infalível. Na atuação dos agrônomoseducadores, o equívoco que se repete é o de se achar possível uma capacitação dos camponeses com uma visão ingênua da técnica, como se fosse possível simplesmente substituir um conhecimento por outro. Desconsidera-se que a técnica e a ciência estão histórica e socialmente condicionadas, assim como o conhecimento experiencial do camponês.

Em confluência, Walsh (2009) acredita que a ciência seja um dos fundamentos centrais do projeto da colonialidade/modernidade. Ela "contribuiu de forma vital ao estabelecimento e manutenção da histórica e atual ordem hierárquica racial, na qual os brancos, e especialmente homens brancos europeus, permanecem superiores" (WALSH, 2009, p. 12). Faz-se necessária, aponta a autora, a construção de novos marcos epistemológicos que pluralizem e desafiem o conhecimento de caráter totalitário, único e universal da ciência moderna. Propõem-se, assim, novos processos e práticas que revitalizem a aplicação de pensamentos ancestrais e a partir da América Latina para criticamente ler o mundo, ou seja, transgredir a ciência moderna em busca de outras coordenadas epistemológicas. 
Percebe-se em Freire (2020) e Walsh (2009) convergências críticas em relação à neutralidade da ciência e uma postura intelectual de subversão do pensamento monolítico que resulta em invasão cultural e no risco e na revalidação de valores da colonialidade. Trata-se de mais um elo entre a pedagogia crítica freiriana e a perspectiva decolonial.

\section{D) CONSCIENTIZAÇÃO COMO AÇÃO TRANSFORMADORA}

O pensamento de Paulo Freire pressupõe a superação de uma visão fatalista da realidade. Ao longo de sua obra intelectual, o autor argumenta que as contradições sociais são produzidas pelos homens e, portanto, passíveis de serem transformadas. Em todas as suas obras a ideia de transformação se faz presente e conceitos como empoderamento, emancipação e conscientização dos sujeitos oprimidos são indicativos de seu posicionamento político-pedagógico.

Em Extensão ou Comunicação?, o caminho para enfrentar o processo de opressão resultante da antidialogia da extensão é apresentado por Freire (2020) a partir da ideia da conscientização e do papel do educador enquanto agente de transformação. Sua pedagogia ergue-se na proposta de subverter a hierarquização dos saberes, o preconceito epistêmico, a invasão cultural, o silenciamento e a desumanização dos grupos sociais oprimidos, reafirmando o caráter político da educação.

Para Freire (2020, p. 39), a educação popular e comprometida com a prática de liberdade deve ter um objetivo fundamental: "através da problematização do homemmundo ou do homem em suas relações com o mundo e com os homens, possibilitar que estes aprofundem sua tomada de consciência da realidade na qual e com a qual estão". A tomada de consciência por meio da relação dialógica, para Freire (2020), desdobra-se na ação transformadora da realidade e exige do educador uma postura política insurgente.

É importante ressaltar que a tomada de consciência é, na compreensão freiriana, um processo de caráter social, não individual. Ela "não se dá nos homens isolados, mas enquanto travam entre si e o mundo relações de transformação, assim também somente aí pode a conscientização instaurar-se" (FREIRE, 2020, p. 102). Nesse sentido, a conscientização é a ação transformadora capaz de emancipar e empoderar os grupos sociais marcados pelo processo de invasão cultural, pela hierarquização do saber e demais formas de opressão. Ela é o objetivo, portanto, da educação como prática de liberdade.

O papel do educador que assume uma postura crítica e decolonial é colocar em xeque a colonialidade do saber. É compreender seu papel na ação política para a transformação e encontrar (ou abrir) as brechas do mundo moderno/colonial, assim como das suas estruturas enrijecidas, onde seja possível atuar rebelde e insurgentemente. Os movimentos de resistência à colonialidade estão e estiveram presentes em múltiplos contextos da América Latina ao longo de cinco séculos, e apresentam experiências pedagógicas coletivas de conscientização para a ação transformadora, muitas vezes ignoradas. É fundamental que educadores e pesquisadores comprometidos com essa perspectiva olhem para essas experiências 
JOAQUIM, B. dos S.; OLIVEIRA, L. M. P. de.

concretas de educação como prática de liberdade e visualizem, não só uma inspiração, mas também como objetos de pesquisa.

\section{CONSIDERAÇÕES FINAIS}

Este artigo procurou localizar as contribuições da obra Extensão ou Comunicação?, de Paulo Freire, dentro da genealogia da pedagogia decolonial latinoamericana. Suas obras são, no Brasil e no mundo, referência no campo educacional, sendo lidas, relidas, comentadas e analisadas em diversos grupos de pesquisa, dossiês científicos, dissertações e teses. Sua vastidão e profundidade faz com que as análises tomem como referência todo o conjunto da sua produção intelectual, ainda que Pedagogia do Oprimido (2002) seja sua obra mais conhecida e traduzida pelo mundo. Sem dúvida, esta obra é uma grande referência da corrente conhecida como pedagogia crítica e um dos livros mais citados no meio acadêmico.

É possível considerar Extensão ou Comunicação? como uma obra importante para os estudos sobre extensão universitária, divulgação científica, educação popular e educação de jovens e adultos. Os elementos apontados neste artigo pretendem também realçar essa obra à posição de pioneira para a genealogia dos estudos decoloniais. Isso porque, conforme exposto, nela são encontrados elementos mais centrais que representam a convergência do pensamento freiriano e decolonial. São eles: a crítica à suposta neutralidade científica; a invasão cultural como ação de silenciamento e reificação do homem oprimido; a hierarquização do saber e preconceito epistêmico; e a conscientização social como estratégia de transformação.

Nesse sentido, é possível concluir que Extensão ou Comunicação? pode ser considerada, dentro do desenvolvimento do pensamento freiriano, uma obra precursora da pedagogia decolonial, pois apresenta elementos centrais que são base crítica da corrente teórica Modernidade/Colonialidade. Há, é verdade, ausência de outros elementos fundantes dessa corrente, sobretudo a ideia de raça e racialização das relações de poder. No entanto, em obras posteriores, especialmente Pedagogia da Esperança (1992), a questão racial é apresentada como um dos elementos da opressão.

Não constitui parte deste estudo a ideia de que a pedagogia decolonial é simplesmente uma leitura atualizada da pedagogia crítica freiriana. Ambas trazem suas especificidades, associadas aos contextos históricos e lugar de fala de seus autores. No entanto, é importante que se reconheça esta na genealogia daquela para que a pedagogia decolonial seja posicionada como parte de um arcabouço teórico-intelectual que vem se constituindo nos movimentos sociais e culturais de resistência à colonialidade e à opressão. Esta análise referenda a ideia de que o conhecimento não se dá de forma isolada, mas de modo contextual, relacional (em rede) e histórico. 
PAULO FREIRE IN THE GENEALOGY OF DECOLONIAL PEDAGOGY: A READING OF EXTENSION OR COMMUNICATION?

ABSTRACT: This paper is characterized as a theoretical-conceptual study that attempts to discuss the contributions of Paulo Freire's Extension or Communication? within the genealogy of Latin American decolonial pedagogy. Inserted in the Modernity/Coloniality theoretical current, decolonial pedagogy is constituted as a political, social, epistemic, and ethical project, expressed by critical interculturality, which bets on the evocation of previously marginalized knowledge and on an insurgent posture towards the rigid structures resulting from the Modernity/Coloniality binomial. In Extension or Communication?, Paulo Freire presents elements that are part of the bases of this thought, such as criticism of the supposed scientific neutrality; cultural invasion as an action of silencing and reification of the oppressed man; hierarchization of knowledge and epistemic prejudice; and social awareness as a transformation strategy. We conclude that the work can be considered, within the development of Freirian thought, a precursor of decolonial pedagogy.

KEYWORDS: Paulo Freire. Decolonial Pedagogy. Decoloniality.

PAULO FREIRE EN LA GENEALOGÍA DE LA PEDAGOGÍA DESCOLONIAL: UNA LECTURA DE ¿EXTENSIÓN O COMUNICACIÓN?

RESUMEN: El presente artículo se caracteriza por ser un estudio teórico-conceptual que busca discutir los aportes de ¿Extensión o Comunicación? de Paulo Freire dentro de la genealogía de la pedagogía decolonial latinoamericana. Como parte de la corriente teórica de la Modernidad/Colonialidad, la pedagogía decolonial es un proyecto político, social, epistémico y ético, expresado por la interculturalidad crítica, que apuesta por la evocación de saberes antes marginados y por una actitud insurgente frente a las estructuras rígidas resultantes del binomio Modernidad/Colonialidad. En ¿Extensión o comunicación?, Paulo Freire presenta elementos que forman parte de los fundamentos de este pensamiento, como la crítica a la supuesta neutralidad científica; la invasión cultural como acción de silenciamiento y cosificación del hombre oprimido; la jerarquización del conocimiento y el prejuicio epistémico; y la conciencia social como estrategia de transformación. Se concluye que la obra puede considerarse, en el marco del desarrollo del pensamiento freiriano, un precursor de la pedagogía decolonial.

PALABRAS CLAVE: Paulo Freire. Pedagogía Decolonial. Decolonialidad.

\section{NOTAS}

1 - FREIRE, P.. Extensão ou Comunicação? Rio de Janeiro: Paz e Terra, 2020.

2 - A primeira data refere-se ao ano da primeira publicação da obra, e a segunda, ao ano de publicação da edição utilizada como referência para este estudo.

3 - Frantz Fanon (1925 - 1961) foi psiquiatra, filósofo, cientista social e revolucionário martinicano. Sua obra influenciou diversos movimentos políticos e teóricos na África e diáspora africana e 
JOAQUIM, B. dos S.; OLIVEIRA, L. M. P. de.

segue reverberando em nossos dias como referência obrigatória nos estudos culturais e póscoloniais. Suas obras mais influentes são Pele Negra, Máscaras Brancas (1952) e Os Condenados da Terra (1961).

4 - Fals Borda (1925 - 2008) foi um acadêmico colombiano, professor emérito da Universidade Nacional da Colômbia e estudioso do campo e da situação dos trabalhadores rurais. Ficou internacionalmente conhecido como um dos principais teóricos do método de pesquisa da ação participativa e por sua atuação política revolucionária que, desde a década de 1960, influencia os estudos pós-coloniais na América Latina.

\section{REFERÊNCIAS BIBLIOGRÁFICAS}

BERNARDINO-COSTA, J. Saberes Subalternos e Decolonialidade: os sindicatos das trabalhadoras domésticas no Brasil. Brasília: Ed. UnB, 2015. 270 p.

DUSSEL, E. Europa, modernidade e eurocentrismo. In: LANDER, E. A colonialidade do saber: eurocentrismo e ciências sociais. Perspectivas latino-americanas. CLACSO, Consejo Latinoamericano de Ciencias Sociales, Ciudad Autónoma de Buenos Aires, Argentina, 2005. p. 25-34.

FREIRE, P. Pedagogia do Oprimido. Rio de Janeiro: Paz e Terra, 2002. 256 p.

FREIRE, P. Pedagogia da Esperança. Rio de Janeiro: Paz e Terra, 2013. 192 p.

FREIRE, P. Extensão ou Comunicação? Rio de Janeiro: Paz e Terra, 2020. 128 p.

HADDAD, S. O Educador: um perfil de Paulo Freire. São Paulo: Todavia, 1a ed., 2019. 256 p.

IANNI, O. Língua e Sociedade. In: VALENTE, A. (org.). Aulas de Português: perspectivas inovadoras. Petrópolis: Vozes, 2008. p. 11-47.

PENNA, C. Paulo Freire no pensamento decolonial: um olhar pedagógico sobre a teoria póscolonial latino-americana. Revista de Estudos e Pesquisas sobre as Américas, Brasília, v. 8, n. 2, p. 164-180, 2014. Disponível em: <https://periodicos.unb.br/index.php/repam/article/view/16133>. Acesso em: 28 nov. 2020.

SANTOS, B. de S. Para uma sociologia das ausências e uma sociologia das emergências. In: SANTOS, B. de S. (org.). Conhecimento Prudente para uma Vida Decente: 'um discurso sobre a ciência' revisitado. São Paulo: Ed. Cortez, 2006. p. 237-280.

STRECK, D.; MORETTI, C.; ADAMS, T. (orgs.). Fontes da Pedagogia Latino-Americana: heranças (des)coloniais. Curitiba: Appris, 2019. 464 p.

OLIVEIRA, L. F. O que é uma educação decolonial? Revista Nuevamérica, Buenos Aires, n. 149, p. 35-39, 2016. 
MARTINS, P. Confluencias entre el pensamiento de Frantz Fanon y de Paulo Freire. EI surgimiento de la educación popular en el marco de la situación colonial. Educação, Santa Maria, v. 37, n. 2, p. 241-255, maio/ago. 2012. Disponível em: $<$ https://periodicos.ufsm.br/reveducacao/article/view/3250 >. Acesso em: 2 dez. 2020.

MIGNOLO, W. Histórias Locais/Projetos Globais: colonialidade, saberes subalternos e pensamento liminar. Belo Horizonte: Ed. UFMG, 2003. 505 p.

MOTA NETO, J. C. Paulo Freire e Orlando Fals Borda na genealogia da pedagogia decolonial latino-americana. FOLIOS - Revista de Universidad Pedagogica Nacional, Colombia, v. 1, n. 48, p. 4-13, 2018. Disponível em: <http://www.scielo.org.co/pdf/folios/n48/0123-4870-folios48-00003.pdf>. Acesso em: 28 nov. 2020.

WALSH, C.; OLIVEIRA, L. F.; CANDAU, V. M. Colonialidade e Pedagogia Decolonial: para pensar uma educação outra. Arquivos Analíticos de Políticas Educativas, Tempe-Arizona, v. 26, n. 83, p. 1-16, 2018. Disponível em: <https://epaa.asu.edu/ojs/article/view/3874 > . Acesso em: 3 dez. 2020

WALSH, C. Interculturalidade Crítica e Pedagogia Decolonial: In-surgir, re-existir e re-viver. In: CANDAU, V. M., Educação intercultural na América Latina: Entre concepções, tensões e propostas. Rio de Janeiro: 7 letras, 2009. p. 12-44.

BRUNO dOS SANTOS JOAQUIM: Doutorando e mestre em Educação pela Universidade Federal do Estado de São Paulo (EFLCH -UNIFESP). Possui graduação em Ciências Sociais pela Universidade Estadual Paulista Júlio de Mesquita Filho (UNESP) e especialização em Ética, Valores e Cidadania na Escola pela Universidade de São Paulo (USP). Atualmente é Professor e Coordenador do Colésio Jean Piaget - Santos.

Orcid: https://orcid.org/0000-0002-6334-958X

E-mail: bruno.joaquim@unifesp.br

LuCILA Maria Pesce de Oliveira: Doutora (2003) e mestre (1999) em Educação: Currículo, pela Pontifícia Universidade Católica de São Paulo (PUC/SP), com pós-doutorado (2007) em Filosofia e História da Educação, pela Universidade Estadual de Campinas (UNICAMP); bacharel e licenciada em Letras - Português e Inglês (1985), pela Universidade Presbiteriana Mackenzie (UPM). Professora Associada do Departamento de Educação da Universidade Federal de São Paulo (UNIFESP); professora do quadro permanente do Programa de Pós-Graduação em Educação da UNIFESP.

Orcid: https://orcid.org/0000-0002-2562-2012

E-mail: lucila.pesce@unifesp.br

Este periódico utiliza a licença Creative Commons Attribution 3.0, para periódicos de acesso aberto (Open Archives Initiative - OAI). 